
PNQM18

\title{
DESENVOLVIMENTO DE MÉTODO ANALÍTICO POR CROMATOGRAFIA LÍQUIDA DE ALTA EFICIÊNCIA PARA AS FOLHAS DE Symphytum officinale LINN.
}

\author{
W. A. V. DA SILVA ${ }^{1}$, M. R. S. BRITTO ${ }^{1,2}$, M. R. A. FERREIRA ${ }^{1,2}$, L. A. L. SOARES ${ }^{1,2}$
}

${ }^{1}$ Universidade Federal de Pernambuco, Laboratório de Farmacognosia, Departamento de Ciências Farmacêuticas

2 Universidade Federal de Pernambuco, Centro de Biociências, Programa de Pósgraduação em Inovação Terapêutica

E-mail para contato:wli27@yahoo.com.br

RESUMO - Symphytum officinale L. (Boraginaceae) conhecida como confrei, é bastante utilizada pertinente as suas propriedades terapêuticas, assim como à presença dos seus fitoconstituintes. Em razão do crescente uso de plantas medicinais, se faz necessário o controle de qualidade da droga vegetal, para obtenção do perfil de seus compostos e posterior quantificação. Dessa forma, o objetivo do trabalho foi obter o perfil do extrato das folhas de S. officinale por Cromatografia Líquida de Alta Eficiencia (CLAE). As análises evidenciaram a presença de alantoína e flavonoides, de acordo com os tempos de retenção e espectros de varredura dos picos correspondentes. A metodologia apresentou boa eficiência para separação e detecção da alantoína e flavonoides presentes na matriz, possibilitando sua identificação e quantificação, mostrando adequabilidade para a finalidade da proposta.

Palavras Chave: CLAE. Confrei. Alantoina.

ABSTRACT - Symphytum officinale L. (Boraginaceae) known as confrei, is widely used as its therapeutic properties due to the presence of its phytochemicals. Due to the increasing use of medicinal plants, analytical tools are necessary to control the quality of the such herbal materials. The chemical profiles play a key role on the qualitative and quantitaive evalution of herbal drugs Thus, the objective of this work was the evaluation of chemical profile of the extract from leaves of $S$. officinale by High Performance Liquid Chromatography (HPLC). The data confirmed the presence of allantoin and flavonoids, according to retention times and scanning spectra of the corresponding peaks. The methodology showed good efficiency for the separation and detection of allantoin and flavonoids in the herbal matrix, allowing their identification and quantification, showing the method suitability for the analyse proposed.

Keywords: HPLC. Confrei. Allatoin. 


\section{INTRODUÇÃO}

Symphytum officinale L. é popularmente conhecida como confrei, pertence a família Boraginaceae, é bastante utilizada devido as suas propriedades medicinais, tais como anti-inflamatória, cicatrizante e hidratante (PILLEGGI et al., 2002) antisséptica, bacteriana, fungicida e calmante (RAHAL et al., 2001). Essas atividades estão relacionadas à presença dos seus fitoconstituintes. Já foram relatados flavonoides, esteroides e triterpenoides (TOLEDO et al., 2006) e os alcaloides pirrolizidinicos (BIAVATTI; MIRANDA, 2017). A identificação e quantificação de compostos químicos específicos (marcadores) é uma das estratégias mais importante para o controle de qualidade. Entre os métodos analíticos destinados a quantificação de compostos químicos em fitoterápicos destaca-se a cromatografia liquida de alta eficiência (HPLC) acoplada a detector de arranjo de diodos (DAD) permite o registro de dados de absorbância do ultravioleta ao visível, fornecendo o espectro de varredura, possibilitando a identificação e análise dos fitoconstituintes presentes na matriz (PRATHAP et al., 2013).

Diante do exposto, o propósito desse trabalho foi desenvolver e otimizar um método para análise dos constituintes das folhas de $S$. officinale por CLAE-DAD, para o emprego no controle de qualidade da espécie vegetal.

\section{MATERIAIS E MÉTODOS}

\subsection{Material Vegetal}

As folhas de Symphytum officinale L. foram coletadas em Gravatá (PernambucoBrasil), entre 8:00 e 9:00 h da manhã. O material botânico identificado no Herbário Dárdano de Andrade Lima do Instituto Agronômico de Pernambuco, onde foi depositada uma exsicata sob número 91194 . Em seguida, o material vegetal foi submetido à secagem em estufa de ar circulante (Luca 82/480, Lucadema ${ }^{\circledR}$ ) sob temperatura de $40{ }^{\circ} \mathrm{C}$ durante $96 \mathrm{~h}$. Em seguida, o material foi pulverizado em moinho de facas tipo Willey (Modelo 340 série $100 / 08$, Adamo $^{\circledR}$ ) com malha de 10 mesh.

\subsection{Obtenção da Solução Extrativa}

$1,0 \mathrm{~g}$ do material vegetal foi transferido para balão de fundo redondo (125 mL) e submetido à extração sob refluxo em banho maria (Lucadema ${ }^{\circledR}$ ) por $20 \mathrm{~min}$, a temperatura de $85{ }^{\circ} \mathrm{C}$, utilizando $15 \mathrm{~mL}$ da etanol $70 \%(\mathrm{v} / \mathrm{v})$. Após o primeiro ciclo, a solução foi filtrada com auxílio de algodão para balão volumétrico de $50 \mathrm{~mL}$, e, o resíduo+algodão foram submetidos a novo ciclo de extração por mais $20 \mathrm{~min}$, repetindo o processo por 3 vezes. Após resfriamento a temperatura ambiente, as frações foram reunidas em balão volumétrico de $50 \mathrm{~mL}$ e o volume foi aferido com o mesmo solvente.

\subsection{Condições Cromatográficas}

Os ensaios foram realizados em Cromatógrafo Líquido (Ultimate 3000, Thermo Fisher Scientific ${ }^{\mathbb{B}}$ ), acoplado a um detector de arranjo de fotodiodo (DAD; Thermo Fisher Scientific ${ }^{\circledR}$ ) e equipado com bomba binária (HPG-3x00RS, Thermo Fisher Scientific $^{\circledR}$ ), degaseificador e amostrador automático equipado com um loop de $20 \mu \mathrm{L}$ (ACC-3000, Thermo Fisher Scientific ${ }^{\circledR}$ ). As análises foram conduzidas com coluna $\mathrm{C}_{18}$ $(250 \mathrm{~mm} \times 4,6 \mathrm{~mm}$ d.i., $5 \mu \mathrm{m})$ Dionex ${ }^{\circledR}$ equipada com pré-coluna $\left(\mathrm{C}_{18}\right.$ de $4 \mathrm{~mm} \times 3,9$ $\mu \mathrm{m}$; Phenomenex ${ }^{\circledR}$ ). A fase móvel foi composta por água ultrapura (Purelab Classic UV, Elga $\left.^{\circledR}\right)$ (solvente A) e acetonitrila grau HPLC $\left(\right.$ Tedia ${ }^{\circledR}$ ) (solvente B). As análises foram realizadas com fluxo de fase móvel igual a $1,0 \mathrm{~mL} / \mathrm{min}$, segundo o gradiente: $0-5 \mathrm{~min}$ : 
$1 \% \mathrm{~B}, \quad 5-10$ min: $1-100 \% \mathrm{~B}, 10-15$ min: $100 \% \mathrm{~B}$ e $15-20$ min: $100-1 \% \mathrm{~B}$. Os cromatogramas foram obtidos em temperatura igual a $25^{\circ} \mathrm{C}$; e com comprimento de onda igual a $210 \mathrm{~nm}$ e $350 \mathrm{~nm}$.

\subsection{Avaliação do método}

Para a avaliação do método uma alíquota de $1 \mathrm{~mL}$ da Solução Estoque (SEA) foi transferida para balão volumétrico de $10 \mathrm{~mL}$ e o volume aferido com a solução metanólica $50 \%$ (v/v) (concentração igual a $2000 \mu \mathrm{g} / \mathrm{mL}$ ). Por fim, a solução foi filtrada em filtro de PVDF 0,45 $\mu \mathrm{m}$ para vials. Foi utilizado como padrão a alantoína (Sigma ${ }^{\circledR}$ ), sendo pesados $10 \mathrm{mg}$ para balão volumétrico de $10 \mathrm{~mL}$ e diluído com a solução metanólica 50\% (v/v) obtendo a Solução Estoque do Padrão (SEP). Uma alíquota de 0,1 $\mathrm{mL}$ da solução (SEP) foi transferida para balão volumétrico de $10 \mathrm{~mL}$ e o volume aferido com a solução metanólica $50 \%$ (v/v) (concentração igual a $10 \mu \mathrm{g} / \mathrm{mL}$ ).

Por fim, a solução foi filtrada em filtro de PVDF $0,45 \mu \mathrm{m}$ para vials. Adicionalmente, uma solução contendo quantidades da solução amostra (1 mL) e solução do padrão $(0,1 \mathrm{~mL})$, foram transferidos para balão volumétrico de $10 \mathrm{~mL}$, para confirmar a presença de alantoína na amostra. Ao final, a solução foi filtrada em filtro de PVDF $0,45 \mu \mathrm{m}$ para vials.

\section{RESULTADOS E DISCUSSÃO}

De acordo com a análise preliminar realizada para obter o perfil do extrato hidroalcoólico das folhas de $S$. officinale, foi possível observar o pico correspondente a presença de alantoína em aproximadamente 3,20 min. A figura 1 traz os cromatogramas referentes ao extrato de $S$. officinale (1), extrato de $S$. officinale fortificado com o padrão de alantoína (2) e o padrão alantoína (3). Dessa forma foi possível confirmar a presença de alantoína na amostra, pela co-injeção do padrão com a amostra, resultando em aumento de área e pelo tempo de retenção do pico correspondente.

Figura - Cromatogramas do extrato de $S$. officinale (1), extrato de S. officinale fortificado com o padrão de alantoína (2) e o padrão alantoína (3), evidenciados em 210 $\mathrm{nm}$.

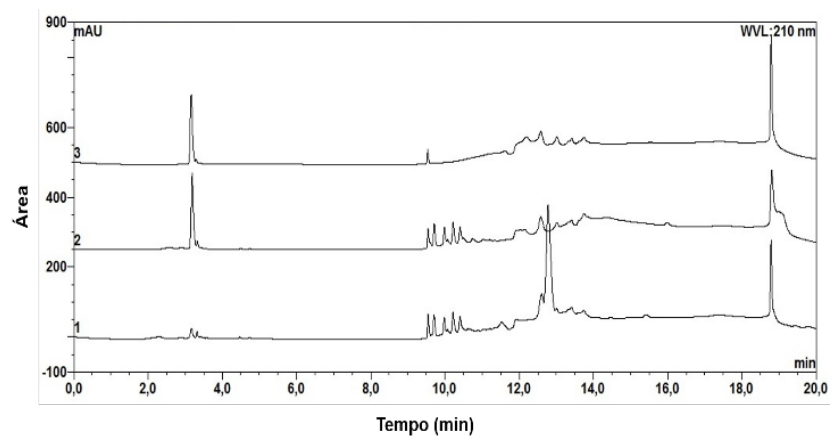

Como o extrato também foi monitorado em $350 \mathrm{~nm}$ (Figura 2), foram observados dois picos com espectro de varreduras semelhantes à classe de flavonoides, com máximos de absorção correspondentes as bandas I e II. O primeiro pico, em 10,41 min, apresentou máximos de absorção em 204.6/256.6/355.5; já o segundo, com $\mathrm{T}_{\mathrm{R}}$ de $12,78 \mathrm{~min}$ com máximos em 198.0/327.7. 
Figura - Cromatograma do extrato de S. officinale evidenciado em $350 \mathrm{~nm}$.

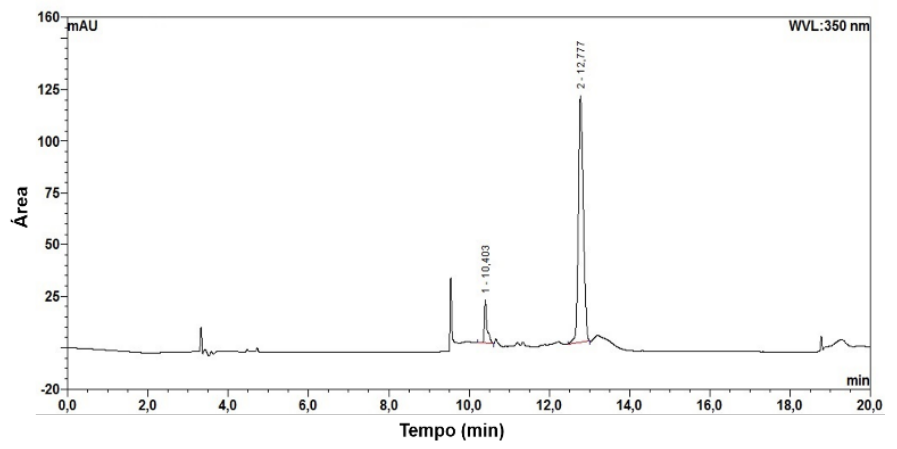

\section{CONCLUSÃO}

A metodologia desenvolvida por CLAE-DAD, para o extrato bruto das folhas de Symphytum officinale L., apresentou boa eficiência de separação e detecção dos constituintes presentes no derivado vegetal. Porém, a metodologia ainda necessita de validação para assegurar a precisão e reprodutibilidade das respostas analíticas viabilizando a sua aplicação ao controle de qualidade de folhas de Symphytum officinale L.

\section{REFERÊNCIAS}

BIAVATTI, M. W.; MIRANDA, R. P. Alcalóides pirrolizidínicos. In: SIMÕES, C.M.O.(Org) et al. Farmacognosia do produto natural ao medicamento. Porto Alegre:Artmed, cap. 25, p. 389 - 402, 2017.

GOLDMAN, R. S.; FREITAS, P. C. D.; OGA, S. Wound healing and analgesic effect of crude extracts of Symphytum officinale in Rats. Fitoterapia, v. 56, n. 6, p. 323-9, 1985.

PILEGGI, M.; RAIMAN, P. M.; MICHAELI, A.; BEATRIZ, S.; BOBATO. V., Ação antimicrobiana e intraendolifica em Symphytum oficinale L. Biolog. Health Sci., v. 8, n. 1, p. 47-55, 2002.

RAHAL, E. A. L. S. S.; ROCHA, N. S.; BLESSA, E. P.; IWABE, S.; CROCI, A. J. Pomada orgânica natural ou solução isotônica no tratamento de feridas limpas em ratos. Ciênc. Rural, v. 31, n. 6, p. 10071011, 2001.

TOLEDO, A. C. O; DUARTE, M. R.; NAKASHIMA, T. Caracterização morfoanatômica de raízes e rizomas de Symphytum officinale L. (Boraginaceae). Rev. Bras. Farmacogn., v. 16, p. 185-191, 2006.

\section{AGRADECIMENTOS}

Os integrantes agradecem a FACEPE (APQ-0493- 4.03/14) e ao CNPq (308386/20159). 